Article

\title{
Application of Methods to Assess Animal Welfare and Suffering Caused by Infectious Diseases in Cattle and Swine Populations
}

\author{
Søren Saxmose Nielsen*(D), Hans Houe, Matthew Denwood, Liza Rosenbaum Nielsen (D), Björn Forkman (D), \\ Nina Dam Otten (D) and Jens Frederik Agger
}

Section for Animal Welfare and Disease Control, Department of Veterinary and Animal Sciences, University of Copenhagen, 1870 Frederiksberg C, Denmark; houe@sund.ku.dk (H.H.); md@sund.ku.dk (M.D.); liza@sund.ku.dk (L.R.N.); bjf@sund.ku.dk (B.F.); nio@sund.ku.dk (N.D.O.); jfa@sund.ku.dk (J.F.A.)

* Correspondence: saxmose@sund.ku.dk

Citation: Nielsen, S.S.; Houe, H.; Denwood, M.; Nielsen, L.R.; Forkman, B.; Otten, N.D.; Agger, J.F. Application of Methods to Assess Animal Welfare and Suffering Caused by Infectious Diseases in Cattle and Swine Populations. Animals 2021, 11, 3017. https://doi.org/10.3390/ ani11113017

Academic Editors: Mrigendra Rajput, Mahmoud M. Naguib, Mehdi Soltani and Roy Neville Kirkwood

Received: 7 September 2021

Accepted: 18 October 2021

Published: 20 October 2021

Publisher's Note: MDPI stays neutral with regard to jurisdictional claims in published maps and institutional affiliations.

Copyright: (c) 2021 by the authors Licensee MDPI, Basel, Switzerland. This article is an open access article distributed under the terms and conditions of the Creative Commons Attribution (CC BY) license (https:/ / creativecommons.org/licenses/by/ $4.0 /)$.
Simple Summary: Infectious disease control in livestock is often motivated by food safety concerns and economic impact. However, most diseases also affect animal welfare. We established an approach to quantify the welfare effect of infectious diseases in cattle (three diseases) and pigs (two diseases). A "suffering score" was established based on the aggregation of severity, duration, and frequency of clinical entities of the diseases. The resulting suffering scores were then used to compare the welfare impact of the different diseases and for comparison to other common welfare hazards. For example, the approach suggested that bovine viral diarrhoea and paratuberculosis are more severe for cattle than infectious bovine rhinotracheitis. In pigs, porcine reproductive and respiratory syndrome has a much bigger welfare impact than Aujeszky's disease, assuming all diseases remain endemic.

Abstract: Control of infectious diseases in livestock has often been motivated by food safety concerns and the economic impact on livestock production. However, diseases may also affect animal welfare. We present an approach to quantify the effect of five infectious diseases on animal welfare in cattle (three diseases) and pigs (two diseases). We grouped clinical manifestations that often occur together into lists of clinical entities for each disease based on literature reviews, and subsequently estimated "suffering scores" based on an aggregation of duration, frequency, and severity. The duration and severity were based on literature reviews and expert knowledge elicitation, while frequency was based mainly on estimates from the literature. The resulting suffering scores were compared to scores from common welfare hazards found under Danish conditions. Most notably, the suffering scores for cattle diseases were ranked as: bovine viral diarrhoea and infection with Mycobacterium avium subsp. paratuberculosis > infectious bovine rhinotracheitis, and for pigs as: porcine respiratory and reproductive syndrome $>$ Aujeszky's disease. The approach has limitations due to the limited data available in literature and uncertainties associated with expert knowledge, but it can provide decision makers with a tool to quantify the impact of infections on animal welfare given these uncertainties.

Keywords: animal welfare; Aujeszky's disease; bovine viral diarrhoea; infectious bovine rhinotracheitis; Mycobacterium avium subsp. paratuberculosis; porcine respiratory and reproductive syndrome

\section{Introduction}

Infectious diseases are common in livestock, where they may be controlled or eradicated due to their impact on food security, food safety, farm economy, and other types of societal impact. These motives have been the main drivers behind the organised control of many infectious diseases in livestock [1]. However, animal welfare is also a reason mentioned in the European Union Animal Health Law [2], a regulation that was adopted by the European Parliament in 2016 and implemented in April 2021. Signs of disease have been associated with animal welfare consequences in the individual, or at group level, and are 
often included in animal welfare protocols, especially those that focus on input variables (e.g., in Welfare Quality ${ }^{\circledR}[3]$ and KTBL (Das Kuratorium für Technik und Bauwesen in der Landwirtschaft e.V.) [4]. However, since these protocols focus on assessing the welfare on farm, often by non-veterinarians, it is clinical signs that are included in the protocols, rather than the diseases. To our knowledge, the impact of livestock diseases on animal welfare has not been quantified systematically, neither at individual nor at population level, and no standard methods exist to allow for such animal welfare impact assessments.

Infectious diseases can affect animal welfare in multiple ways, e.g., reduced comfort of the individual due to the acute pathologies caused by the infectious agent resulting in clinical signs such as fever, weakness, and diarrhoea, or long-term effects where weight loss and general unthriftiness may place the animal in a lower ranking in an animal group. Reduced animal welfare may also result from lack of social interaction due to disease control measures imposed on the entire population, e.g., if calf and dam are separated shortly after calving to mitigate the risk of transmission from dam to calf.

The aim of this project was to develop and illustrate a new approach to assess the impact of infectious diseases on animal welfare in livestock. The five diseases are bovine virus diarrhoea (BVD), infectious bovine rhinotracheitis (IBR) and infection with Mycobacterium avium subsp. paratuberculosis (MAP) in dairy cattle, and Aujeszky's disease and porcine respiratory and reproductive syndrome (PRRS) in pigs. These diseases were primarily selected due to the long-standing legal requirements to control these diseases in Denmark, but not necessarily in the European Union. Furthermore, the diseases are quite different and represent different areas of potential suffering.

The objectives of the study (exemplified with these five diseases) were to:

a. develop a measurement scale for assessing the level of animal welfare and the impact of disease on animal welfare (pain and general discomfort);

b. estimate the duration and severity scores for each disease and clinical entity based on expert knowledge elicitation (EKE);

c. estimate animal suffering scores for common non-infectious welfare challenges (such as broken femur, lack of access to water, separation of dam and offspring) in pig and cattle production for comparison and perspective;

d. combine duration, severity, and frequency into an aggregated suffering score.

\section{Materials and Methods}

\subsection{Overview}

The work was based on a summary of the literature on disease manifestations of each of the five diseases. These were grouped into different "clinical entities" (i.e., disease stages with clinical signs that typically occur concurrently for the disease in question) and a summary of the occurrence and duration of the diseases based on literature reviews and EKEs. The assessment using EKEs was performed based on a derivative of the Delphi method [5], which has previously been used for infectious diseases and animal welfare in connection with the Animal Health Law [6-9]. The approach consists of a two-step individual assessment followed by collective behavioural aggregation [5].

The term "clinical entity" is used to cover disease manifestations with multiple clinical signs present at the same time, e.g., "diarrhoea and emaciation" or "nasal discharge and pneumonia". Different clinical entities of the same disease were assumed to be mutually exclusive.

\subsection{Literature Summary of Diseases and Their Clinical Entities}

Literature reviews for BVD virus, IBR virus, and MAP infections in dairy cattle and Aujeszky's disease and PRRS in pigs have previously been carried out (see [10] and Supplementary Materials, where extensive literature searches are provided), giving information on clinical entities and the related typical signs as well as their duration and frequency. The clinical entities and associated clinical signs for relevant age groups are listed in Table 1. An additional ten welfare hazards (five for cattle and five for pigs) not related to the infectious diseases were also selected for assessment for comparative purposes (Table 2). 
Table 1. Typical clinical signs stratified by clinical disease entities and age group for each of the five diseases ${ }^{1}$, as described in the literature.

\begin{tabular}{|c|c|c|c|}
\hline Disease & Clinical Entity & Age Group & Typical Signs \\
\hline \multirow{16}{*}{ BVD } & \multirow{3}{*}{ Transient infection } & Calves & Diarrhoea \\
\hline & & Heifers & Diarrhoea \\
\hline & & Cows & Diarrhoea \\
\hline & \multirow{3}{*}{$\begin{array}{l}\text { Transient infection } \\
\text { with erosions }\end{array}$} & Calves & Mucosal erosions \\
\hline & & Heifers & Mucosal erosions \\
\hline & & Cows & Mucosal erosions \\
\hline & \multirow{4}{*}{ Co-morbidity } & Heifers & Retained placenta \\
\hline & & Cows & Retained placenta \\
\hline & & Calves & Respiratory disease, diarrhoea \\
\hline & & Heifers & Respiratory disease, diarrhoea \\
\hline & \multirow{2}{*}{ Repeat breeding } & Heifers & Subclinical \\
\hline & & Cows & Subclinical \\
\hline & \multirow{2}{*}{ Abortion } & Heifers & Abortion early or late after infection \\
\hline & & Cows & Abortion early or late after infection \\
\hline & Congenital defects & Newborn & Miscellaneous malformations incl. congenital tremor and weak calves \\
\hline & PI: mucosal disease & Calves \& heifers & Severe diarrhoea and erosion \\
\hline \multirow{3}{*}{ IBR } & Acute phase 1 & \multirow[t]{2}{*}{ Calves, heifers \& cows } & $\begin{array}{l}\text { Reduced appetite, dullness, salivation, nasal and ocular discharge, lachrymation, conjunctivitis, rapid respiration, } \\
\text { coughing and pyrexia. May lead to death }\end{array}$ \\
\hline & Acute phase 2 & & Diarrhoea and dehydration \\
\hline & Abortion & Cows & Abortion during 2nd and 3rd trimesters \\
\hline \multirow{5}{*}{ MAP } & & & Weight loss/poor condition (BCS 1-2)/chronic wasting \\
\hline & Stage III & Cows & Intermittent diarrhoea \\
\hline & & & Emaciation (BCS 0-1) \\
\hline & Stage IV & Cows & Pipe stream diarrhoea \\
\hline & Stage IV & Cows & Lethargy \\
\hline
\end{tabular}


Table 1. Cont.

\begin{tabular}{|c|c|c|c|}
\hline Disease & Clinical Entity & Age Group & Typical Signs \\
\hline \multirow{6}{*}{ Aujeszky's } & Encephalitis & Piglets infected in utero & \multirow{2}{*}{$\begin{array}{l}\text { Weak piglets; shaking/shivering/sudden death } \\
\text { Lethargy; weakness / appetite loss; incoordination/ convulsions (vomiting, diarrhoea) incl. febrile response (up } \\
\text { to } 42^{\circ} \mathrm{C} \text { ) }\end{array}$} \\
\hline & Encephalitis & Piglets $(<3$ weeks $)$ & \\
\hline & Encephalitis & \multirow{4}{*}{$\begin{array}{l}\text { Weaners \& finisher pigs } \\
\text { ( }>3 \text { weeks) } \\
\text { Adult pigs } \\
\text { Weaners \& finishers ( }>3 \text { weeks) }\end{array}$} & Loss of appetite; somnolence; trembling/convulsions; paralysis; high temperature (up to $42^{\circ} \mathrm{C}$ ) \\
\hline & Encephalitis & & Incoordination of hind limbs and febrile response (up to $42{ }^{\circ} \mathrm{C}$ ) \\
\hline & Respiratory signs & & Sneezing/ nasal discharge; coughing; dyspnoea \\
\hline & Reproduction & & Vaginal discharge; mummification; agalactia \\
\hline \multirow{3}{*}{ PRRS } & \multirow{3}{*}{ Acute infection } & Sows \& boars & Anorexia, fever, lethargy, respiratory difficulties, cyanosis \\
\hline & & $\begin{array}{l}\text { Nursery } \\
\text { piglets }\end{array}$ & $\begin{array}{l}\text { Poor growth, anorexia, fever, respiratory distress, diarrhoea, anaemia, congenital abnormalities, weakness, ataxia, } \\
\text { haemorrhage, immunomodulation }\end{array}$ \\
\hline & & Weaners \& finishers & Transient anorexia, respiratory disorders and discolouration of the ears \\
\hline
\end{tabular}

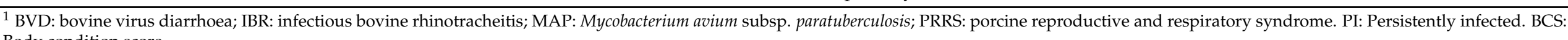
Body condition score.

Table 2. Scenario description of ten welfare hazards occurring in dairy cattle and pig production used for comparison.

\begin{tabular}{|c|c|c|}
\hline Hazard & Age Group & Scenario \\
\hline No access to water-cattle & Cows & Dairy cattle left with no access to water due to broken pipes \\
\hline Broken femur-cattle & Cows & Dairy cow falls on slippery floor and is left until euthanised \\
\hline Broken femur-pigs & Sows & Sow falls on slippery floor with other sows and is pushed around \\
\hline Weather conditions are too hot & Cows & Warm summer days in Denmark $\left(>25^{\circ} \mathrm{C}\right)$ interrupted by cooler nights with no access to shade during the daytime \\
\hline Separation of cow and calf & Calves & Calf separated within $24 \mathrm{~h}$ of birth \\
\hline Weaning of piglets & Piglets & Piglets weaned 3-4 weeks after birth \\
\hline Tail biting & $\begin{array}{l}\text { Weaners and } \\
\text { finishers }\end{array}$ & Ongoing and severe tail biting (part of tail bitten off, blood present) \\
\hline Crating of sows & Sows & Sows crated in farrowing section (from 1 week prior to farrowing) \\
\hline Feed restriction & Sows & $\begin{array}{l}\text { Feed provision reduced to } 30 \% \text { of ad lib during gestation. Sows are housed together, but most often feed provision } \\
\text { is individual }\end{array}$ \\
\hline
\end{tabular}




\subsection{Animal Welfare Scoring and Assessment}

\subsubsection{Expert Knowledge Elicitation of Severity and Duration}

Quantification of animal welfare is a challenge, but expert judgement is commonly used in food and feed safety risk assessments, and has also been used in animal welfare judgements $[7,11]$. Expert elicitation methods include the Sheffield method, where behavioural aggregation is obtained through face-to-face discussions between experts, and the Cooke method, which employs mathematical aggregation. The Delphi method lies in between these options, as it allows some restricted interaction between experts [5]. The step-wise EKE was carried out as listed in the Box 1.

Box 1. Stepwise expert knowledge elicitation.

An EKE with subsequent behavioural aggregation among the experts was carried out according to the following steps. Each of the eight experts (B.F., H.H., J.F.A., L.R.N., M.D., N.D.O., S.S.N., and a final year veterinary student) were asked to create a score for each clinical entity based on the following instruction: Imagine that "severity" is described on a scale of 0 to 10 , where 0 is "no noticeable effect" and 10 is "unbearable pain or other negative effect" for the animal. "Mastitis" in cattle was set as a reference value of 5 .

The question to be addressed for each clinical entity was then:

Imagine that 1000 animals are affected with this clinical entity for a period with the duration described by duration_q1, duration_q2 and duration_q3, i.e., the interquartile range (q1-q3) and the median (q2). What would be the distribution of the combined severity of the typical signs during this period? Please describe the severity distribution with the 2.5 percentile, the mode (most likely), and the 97.5 percentile.

This first step was carried out for each disease and constituted the individual assessment. Step 2 was a group discussion, which occurred in virtual group meetings (due to restrictions imposed due to the national management of SARS-CoV-2 circulation in Denmark in 2020). The participants saw the scores of the others and were asked to verbally rationalise their choices, ask questions to other participants about their motivation, and ultimately re-score if they felt they had not taken sufficient aspects into account during their initial individual scoring. It was stressed that all participants were entitled to keep their original score. Finally, a distribution of scores for each clinical entity was included.

A similar approach was taken for the selected non-infectious welfare hazards. Furthermore, for each clinical entity and welfare hazard, the duration of the impact on animal welfare within each clinical entity or hazard was agreed among the experts.

\subsubsection{Disease Occurrence}

Prevalence or incidence data from an endemic situation with the disease in question was extracted from the literature (see below) and constituted the baseline data for disease frequency. Disease occurrence was calculated as the total number of events per year per population unit for a given clinical entity/welfare hazard in a given animal group. The following groups of animals were used: cows (female animals $>2$ years), heifers 1-2 years, heifer calves $<1$ year, bull calves $<1$ year, and foetuses (animals preterm) composed the cattle group; sows (females $>201$ days), boars (>201 days), finishers (99-201 days), weaners (25-98 days), and piglets ( $0-25$ days) were included for the pigs.

BVD: The calculations for postnatal infections and foetal infections were performed separately. For postnatal infections and in endemic situations with no systematic control programme in place, the annual incidence risk of infection has been estimated at $34 \%$, which was shown to be similar across age groups [12]. This annual incidence risk was then converted to an annual incidence risk for each clinical entity (i.e., the effective incidence risk (EIR), where the occurrence of the specific clinical entity was estimated based on the occurrence of infection and information in literature). As some clinical entities (e.g., retained placenta and abortions) only occur if the animal is infected during certain risk periods, it is necessary to take this risk period into account. As the calculations addressing risk periods are easier to perform using rates, the incidence risk was changed to incidence rate, and 
then risk periods were addressed and the rate was re-calculated to an annual incidence risk. Therefore, the following steps were used:

a. annual incidence risk of infection obtained from the literature;

b. risk of clinical entity occurring if animal is infected during the risk period, based on expert opinion (H.H.);

c. calculation of annual incidence risk of clinical entity $(a \times b)$;

d. calculation of annual incidence rate of clinical entity (i.e., clinical events per animal year at risk): calculated from c) using the formula

$$
I_{\text {rate }}=\frac{-\ln \left(1-I_{\text {risk }}\right)}{t},
$$

where $t$ is the risk period, and $I_{\text {risk }}$ is the annual incidence risk (p. 84 in [13]);

e. estimation of the risk period based on expert opinion (H.H.), measured in years;

f. calculation of the effective incidence rate (EIR) as

$$
E I R=I_{\text {rate }} \times t \text { years, }
$$

in other words, the actual rate given the animal is not at risk for an entire year is therefore expressed as "effective" IR or EIR;

g. conversion of EIR to effective annual incidence risk (EAIR) using:

$$
I_{\text {risk }}=1-e^{I_{\text {rate }} \times t}
$$

(Formula 6.2 in [13]);

h. total number of events = population size $(n=1,000,000)$ multiplied by EAIR.

For foetal infections, a more direct calculation was used. It has been estimated that the risk of foetal infection during the first 3 months of pregnancy is approximately $3 \%$, i.e. the risk of a calf being persistently infected (PI) is 3\% [12]. In order to address the risk of congenital defects being induced during a period of approximately 2 months during pregnancy, a risk of $2 \%$ was used for these animals. After addressing the risk periods, the EIR were then obtained by multiplying these incidence risks with an estimation of the probability that the clinical entity would occur if infected.

IBR: There were no estimates of the annual incidence risk of IBR infection at animal level in the Danish cattle population prior to the initiation of a control and eradication programme in 1985. Therefore, the best expert guess was based on (a) information from 1985 [14] about the number of IBR test-positive dairy cattle herds, the number of dairy cattle herds, and the population of dairy cattle and (b) an estimate of the within-herd incidence risk in test-positive herds in 1995, assuming this would be similar to the withinherd incidence risk in 1985. The estimation was as follows: a recurrent outbreak of IBR in 1995 (after having been eradicated from the Danish cattle population in 1992) in 61 dairy herds comprised 1560 test-positive cattle [15]. An estimate of the population at risk in the 61 dairy herds was based on information about the total number of cattle $(2,090,373)$ and the total number of herds $(30,250)[16]$. This gives an average herd size of $2,090,373 \div 30,250=69.1$ cattle. The population at risk in the 61 dairy herds was therefore estimated to be $61 \times 69.1=4215$ cattle. Thus, in 1995, the estimated annual animal-level incidence risk of being test positive was 1560 cases $\div 4215=0.37$. In 1985, there were approximately 31,773 dairy herds with 896,358 dairy cows, and the number of IBR testpositive dairy herds was 2667 . Based on the above assumptions, the annual incidence risk of IBR infection in 1985 was estimated to be:

$I_{\text {risk }}=(2667$ herds $\times(896,358$ cows $\div 31,773$ dairy herds $) \times 0.37$ cases per cow $) \div$ $(896,358$ cows $)=0.031$ or $3.1 \%$. Based on the literature, it was assumed that all age groups were at the same risk of infection.

The number of clinical events was then calculated based on the probability of the presence of the three clinical entities among those infected (cf. Table 1), i.e., there was a 
$90 \%$ probability of the clinical entity acute phase 1 , a $10 \%$ probability of the clinical entity acute phase 2 , and a $5 \%$ probability of the clinical entity abortion.

MAP: MAP infections were only deemed to be relevant for adult cattle. The annual incidence risk of clinical cases was reported as $3.6 \%$ prior to the establishment of a control programme [17]. This was used to calculate the total number of events per year by multiplying it by the population size for the clinical entity Stage III MAP infection. However, not all cattle will proceed to the clinical entity Stage IV, so the effective annual incidence rate was considered to be only $50 \%$ of the effective annual incidence rate for cattle in Stage III.

Aujeszky's disease: The following age groups were used for pigs: (a) piglets infected in utero; (b) piglets < 3 weeks of age; (c) weaners and finisher pigs ( $>3$ weeks); and (d) adult pigs.

The annual incidence risk of Aujeszky's disease virus infection in Danish pig herds prior to the initiation of the eradication programme in 1982 was reported to be 90 positive herds (Bitsch, 1984) out of a total of 55,000 pig holdings, yielding an annual incidence risk of $0.16 \%$, which was similar across all age groups. Morbidity has been reported to be generally high at $100 \%$ [8], while mortality is considered highest in young animals (e.g., piglets $<3$ weeks $=100 \%$ ) and declining with increasing age (e.g., weaners and finishers $=50 \%$, adult pigs $<5 \%$ ). Adult pigs have a varying morbidity ranging from $10-30 \%$. Based on these estimates, the effective incidence risk prior to eradication of Aujeszky's disease virus from the Danish population was calculated using an annual incidence risk of $0.16 \%$ multiplied by the estimated age-group-specific prevalence of animals showing clinical manifestations among infected pigs.

PRRS: There are four clinical entities for which frequency estimates are needed for PRRS: reproductive issues caused by chronic re-exposure in sows, and acute infection in each of the age groups sows/boars, nursery piglets, and weaners/finishers. Estimating the required frequencies is greatly facilitated by [18], which provides direct estimates for the proportion of animals in Denmark affected with clinical signs (relating to endemic disease), i.e., $5 \%$ for weaners/finishers and $10 \%$ for sows (note: the table given by de Paz [18] states that this is a prevalence estimate, but given the description of the numbers in the text, the interpretation appears to be closer to an incidence risk). These estimates are therefore used directly as the effective incidence risk for chronic re-exposure in sows $(0.05)$ and acute infection in weaners/finishers (0.1). For acute clinical disease in piglets, it was assumed that the proportion of nursery piglets exposed to disease was the same as the chronic re-infection rate in sows, and the approximate ratio of morbidity between sows (reported as $100 \%$ ) and nursery piglets (reported as up to $80 \%$ ) was used to adjust the effective incidence risk to $75 \%$ of $0.01=0.075$. For acute clinical disease in adult pigs, an average morbidity estimate of $27.5 \%$ (based on the $5-50 \%$ range of [19]) was combined with the expert assumption that $1 \%$ of farms experience an epidemic outbreak annually, thus arriving at an effective incidence risk of 0.00275 .

Welfare hazards. The calculation of EAIR for the ten welfare hazards was primarily based on expert judgements.

- No access to water-cattle. This was considered to occur for $1 \%$ of animals annually.

- Broken femur-cows and sows. This was considered to have an EAIR of $0.1 \%$.

- Lying on a concrete floor with no bedding material was considered to occur with an EIR of $1 \%$ of dairy cows per day.

- Weather conditions are too hot. Heat stress generally occurs at $22^{\circ} \mathrm{C}$, and it is considered to affect the majority of dairy cattle when temperatures rise above $25{ }^{\circ} \mathrm{C}$. Therefore, we deemed that heat stress occurs in $90 \%$ of dairy cows when the temperature reaches $25^{\circ} \mathrm{C}$.

- Separation of cow and calf was assumed to occur once for $95 \%$ of calves born to dairy cows, and each cow was assumed to have one calf per year, so the total number of events is equal to the population size $\times 0.95$.

- Weaning piglets at 28 days occurs once in $95 \%$ of piglets born, so the total number of events is equal to the population size $\times 0.95$. 
- Tail biting has a prevalence of $3 \%$ in weaners and finishers, so the total number of events is equal to the population size $\times 0.03$.

- Crating of sows. It was assumed that $95 \%$ of the sow population farrow 2.5 times per year, so the total number of events is $2.5 \times$ population size $\times 0.95$.

- Feed restriction occurs 2.5 times per year in $98 \%$ of the sow population, so the total number of events is $2.5 \times$ population size $\times 0.98$.

For each disease entity, the number of annual events was estimated by multiplying the incidence risk with the population size. In all cases (both disease entities and welfare hazards), the population size used was 1,000,000 for each age group.

\subsection{Aggregation of Suffering Scores Based on Severity, Duration and Occurrence}

Occurrence was aggregated with severity and duration to obtain the total "suffering" score for the specific clinical entity and animal group, i.e., the suffering score was Risk $\times$ Time $\times$ Severity. The risk is equal to the number of cases $\div$ population at risk. Time is measured in units of days. Severity is measured on an ordinal scale of 0 to 10 , where $0=$ not severe and $10=$ maximum severity. This analogue scale represents the human experts' subjective perception of the "amount" of, e.g., pain, dullness, weakness, discomfort, and dizziness associated with the condition.

The suffering scores were estimated using Monte Carlo approximation with 1000 iterations per disease. For each disease and clinical entity, suffering scores were aggregated based on the severity scores (from each expert), duration, and occurrence. Aggregation was performed as follows: for a given disease and clinical entity, a random theoretical animal of a given species and age group was selected. Whether or not the animal had the clinical entity was randomly chosen based on the disease occurrence (total number of events per year). How long the animal would suffer from the disease was then randomly chosen based on the distribution given by the experts. This distribution was derived from the mode and 2.5/97.5 percentiles elicited by the experts and mapped into a triangular distribution fitted using the triangle package [20] for R version 3.6.3 (R Foundation for Statistical Computing, Austria, Vienna).

The total suffering was then calculated by Monte Carlo integration, resulting in an estimated distribution of suffering per clinical entity and expert. The combined expert score was used if no systematic effect of expert was found.

\section{Results}

Animal Welfare Scoring and Assessment

Table 3 shows the distributions of the duration of each clinical entity for each disease and welfare hazard as agreed by the experts through the EKE. These were combined with the calculated number of events for each clinical entity (Table 4) and the combined severity scores from the EKE (Table 5). The distribution of scores for the eight experts are shown in Figure 1. Due to the general overlap, and because no expert seemed to be systematically different from others, the combined scores were used for all subsequent reporting. The severity scores for all clinical entities and welfare hazards are shown in Figure 2. The summarised scores are also shown in Table 6 , and the ranked means of the summarised severity scores are as follows (from lowest to highest): broken femur in cattle $<$ broken femur in pigs $<$ no access to water (cattle) $<$ Aujeszky's disease $<$ tail biting $<$ PRRS $<$ IBR $<$ weaning of piglets $<$ separation of cow and calf $<$ weather conditions are too hot (for cattle) $<$ MAP infection and BVD $<$ cattle lying on concrete floor with no bedding material $<$ crating of sows $<$ feed restriction. These conditions are for the average affected individual for the average duration that this animal would be expected to endure the condition over a year, summarised for the population. 


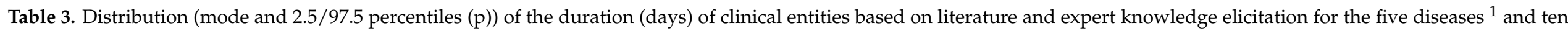
non-infectious welfare hazards.

\begin{tabular}{|c|c|c|c|c|c|c|}
\hline Disease & Clinical Entity & Age Group & Typical Signs & $2.5 p$ & Mode & $97.5 p$ \\
\hline \multirow{12}{*}{ BVD } & \multirow{2}{*}{ Transient infection } & Calves & Diarrhoea & 5 & 10 & 35 \\
\hline & & Heifers \& cows & Diarrhoea & 5 & 10 & 35 \\
\hline & \multirow{2}{*}{$\begin{array}{l}\text { Transient infection } \\
\text { with erosions }\end{array}$} & Calves & Mucosal erosions & 8 & 14 & 45 \\
\hline & & Heifers \& cows & Mucosal erosions & 8 & 14 & 45 \\
\hline & \multirow{3}{*}{ Co-morbidity } & Calves & Respiratory disease, diarrhoea & 2 & 3 & 14 \\
\hline & & Heifers & Respiratory disease, diarrhoea & 7 & 20 & 56 \\
\hline & & Heifers \& cows & Mastitis, retained placenta & 7 & 20 & 56 \\
\hline & Repeat breeding & Cows & Subclinical & 1 & 4 & 6 \\
\hline & Abortion & Heifers \& cows & Abortion early or late after infection & 1 & 4 & 35 \\
\hline & Congenital defects & Newborn & Miscellaneous malformations incl. congenital tremor and weak calves & 1 & 2 & 3 \\
\hline & PI: animals unthrifty & Calves \& heifers & Weight loss & 100 & 400 & 700 \\
\hline & PI: mucosal disease & Calves \& heifers & Severe diarrhoea and erosion & 4 & 21 & 45 \\
\hline \multirow{3}{*}{ IBR } & \multirow{2}{*}{ Acute phase } & Calves, heifers \& cows & $\begin{array}{l}\text { Reduced appetite, dullness, salivation, nasal and ocular discharge, lachrymation, conjunctivitis, } \\
\text { rapid respiration, coughing and pyrexia. May lead to death }\end{array}$ & 7 & 42 & 100 \\
\hline & & Calves, heifers \& cows & Diarrhoea and dehydration & 7 & 49 & 100 \\
\hline & Abortion & Cows & Abortion during 2nd and 3rd trimesters & 0 & 14 & 30 \\
\hline \multirow{5}{*}{ MAP } & \multirow{3}{*}{ Stage III } & Cows & Weight loss/ poor condition (BCS 1-2)/ chronic wasting & 15 & 120 & 240 \\
\hline & & Cows & Intermittent diarrhoea & 15 & 120 & 240 \\
\hline & & Cows & Emaciation (BCS 0-1) & 1 & 10 & 60 \\
\hline & \multirow{2}{*}{ Stage IV } & Cows & Pipe stream diarrhoea & 1 & 10 & 60 \\
\hline & & Cows & Lethargy & 1 & 4 & 5 \\
\hline \multirow{6}{*}{ Aujeszky's } & Encephalitis & Piglets infected in utero & Weak piglets, shaking/ shivering/ sudden death & 0.1 & 1 & 2 \\
\hline & Encephalitis & Piglets (<3 weeks) & $\begin{array}{l}\text { Lethargy, weakness / appetite loss, incoordination/convulsions (vomiting, diarrhoea) incl. febrile } \\
\text { response (up to } 42^{\circ} \mathrm{C} \text { ) }\end{array}$ & 1 & 4 & 8 \\
\hline & Encephalitis & Weaners \& finishers ( $>3$ weeks) & Loss of appetite, somnolence, trembling/convulsions, paralysis, high temperature (up to $42{ }^{\circ} \mathrm{C}$ ) & 1 & 4 & 8 \\
\hline & Encephalitis & Adult pigs & Incoordination of hind limbs and febrile response (up to $42^{\circ} \mathrm{C}$ ) & 1.5 & 6 & 14 \\
\hline & Respiratory signs & Weaners \& finishers ( $>3$ weeks) & Sneezing/ nasal discharge, coughing, dyspnoea & 1 & 4 & 8 \\
\hline & Reproduction & & Vaginal discharge, mummification, agalactia & 1 & 4 & 8 \\
\hline
\end{tabular}


Table 3. Cont.

\begin{tabular}{|c|c|c|c|c|c|c|}
\hline Disease & Clinical Entity & Age Group & Typical Signs & $2.5 \mathrm{p}$ & Mode & $97.5 p$ \\
\hline \multirow{4}{*}{ PRRS } & Re-exposure & Sows & Reproductive problems incl. abortion, still-birth, and return to service & 2 & 5 & 14 \\
\hline & \multirow{3}{*}{ Acute infection } & Sows \& boars & Anorexia, fever, lethargy, respiratory difficulties, cyanosis & 1 & 1 & 1 \\
\hline & & Nursery piglets & $\begin{array}{l}\text { Poor growth, anorexia, fever, respiratory distress, diarrhoea, anaemia, congenital abnormalities, } \\
\text { weakness, ataxia, haemorrhage, immunomodulation }\end{array}$ & 2 & 7 & 28 \\
\hline & & Weaners \& finishers & Transient anorexia, respiratory disorders and discolouration of the ears & 5 & 6 & 7 \\
\hline \multirow{4}{*}{$\begin{array}{l}\text { Welfare } \\
\text { Hazards- } \\
\text { cattle }\end{array}$} & $\begin{array}{l}\text { No access to } \\
\text { water-cattle }\end{array}$ & Cows & Scenario: dairy cattle left with no access to water due to broken pipes & 0.25 & 1 & 3 \\
\hline & $\begin{array}{l}\text { Lying on concrete } \\
\text { floor with no } \\
\text { bedding material }\end{array}$ & Cows & Scenario: dairy cows resting in a free stall environment & 90 & 1000 & 3000 \\
\hline & $\begin{array}{l}\text { Weather conditions } \\
\text { are too hot }\end{array}$ & Cows & $\begin{array}{l}\text { Scenario: warm summer days }\left(>25^{\circ} \mathrm{C}\right) \text { interrupted by cooler nights. No access to shade during } \\
\text { the daytime }\end{array}$ & 1 & 7 & 21 \\
\hline & $\begin{array}{l}\text { Separation of cow } \\
\text { and calf }\end{array}$ & Calves & Scenario: calf separated within $24 \mathrm{~h}$ of birth & 1 & 5 & 12 \\
\hline \multirow{4}{*}{$\begin{array}{l}\text { Welfare } \\
\text { hazards- } \\
\text { pigs }\end{array}$} & Weaning of piglets & Piglets & Scenario: piglets are weaned 3-4 weeks after birth & 1 & 3 & 8 \\
\hline & Tail biting & Weaners \& finishers & Scenario: ongoing severe tail biting (part of tail bitten off, blood present) & 1 & 5 & 28 \\
\hline & Crating of sows & Sows & Scenario: sows are crated in farrowing section (from 1 week prior to farrowing) & 28 & 32 & 45 \\
\hline & Feed restriction & Sows & $\begin{array}{l}\text { Scenario: feed provision is reduced to } 30 \% \text { of ad lib during gestation. Sows are housed together, } \\
\text { but most often feed provision is individual }\end{array}$ & 80 & 85 & 95 \\
\hline
\end{tabular}

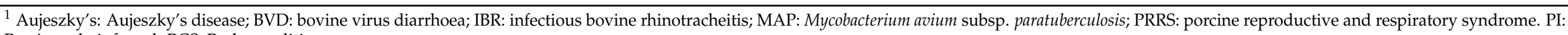
Persistently infected. BCS: Body condition score. 
Table 4. Annual incidence risk (IR) and total number of events (TNE) per 1 million animals for each clinical entity for the five diseases ${ }^{1}$ and ten non-infectious welfare hazards.

\begin{tabular}{|c|c|c|c|c|c|}
\hline Disease & Clinical Entity & Age Group & Typical Signs & IR & TNE \\
\hline \multirow{17}{*}{ BVD } & \multirow{3}{*}{ Transient infection } & Calves & Diarrhoea & 0.03125 & 31,250 \\
\hline & & Heifers & Diarrhoea & 0.034 & 34,000 \\
\hline & & Cows & Diarrhoea & 0.034 & 34,000 \\
\hline & \multirow{3}{*}{$\begin{array}{l}\text { Transient infection } \\
\text { with erosions }\end{array}$} & Calves & Mucosal erosions & 0.006243 & 6243 \\
\hline & & Heifers & Mucosal erosions & 0.0068 & 6800 \\
\hline & & Cows & Mucosal erosions & 0.0068 & 6800 \\
\hline & \multirow{5}{*}{ Co-morbidity } & Heifers & Retained placenta & 0.001710 & 1710 \\
\hline & & Cows & Mastitis & 0.0408 & 40,800 \\
\hline & & Cows & Retained placenta & 0.001710 & 1710 \\
\hline & & Calves & Respiratory disease, diarrhoea & 0.04691 & 46,908 \\
\hline & & Heifers & Respiratory disease, diarrhoea & 0.017 & 17,000 \\
\hline & \multirow{2}{*}{ Repeat breeding } & Heifers & Subclinical & 0.001421 & 1421 \\
\hline & & Cows & Subclinical & 0.001421 & 1421 \\
\hline & \multirow[b]{2}{*}{ Abortion } & Heifers & Abortion early or late after infection & 0.013507 & 13,507 \\
\hline & & Cows & Abortion early or late after infection & 0.013507 & 13,507 \\
\hline & Congenital defects & Newborn & Miscellaneous malformations incl. congenital tremor and weak calves & 0.002 & 2000 \\
\hline & PI: mucosal disease & Calves \& heifers & Severe diarrhoea and erosion & 0.0036 & 3600 \\
\hline \multirow{3}{*}{ IBR } & \multirow[t]{2}{*}{ Acute phase } & Calves, heifers \& cows & $\begin{array}{l}\text { Reduced appetite, dullness, salivation, nasal and ocular discharge, lachrymation, } \\
\text { conjunctivitis, rapid respiration, coughing and pyrexia, may lead to death }\end{array}$ & 0.0279 & 27,900 \\
\hline & & Calves, heifers \& cows & Diarrhoea and dehydration & 0.0031 & 3100 \\
\hline & Abortion & Cows & Abortion during 2nd and 3rd trimesters & 0.0007647 & 765 \\
\hline \multirow{5}{*}{ MAP } & \multirow{3}{*}{ Stage III } & Cows & Weight loss/poor condition (BCS 1-2)/chronic wasting & 0.036 & 36,000 \\
\hline & & Cows & Intermittent diarrhoea & 0.036 & 36,000 \\
\hline & & Cows & Emaciation (BCS 0-1) & 0.018 & 18,000 \\
\hline & \multirow{2}{*}{ Stage IV } & Cows & Pipe stream diarrhoea & 0.018 & 18,000 \\
\hline & & Cows & Lethargy & 0.018 & 18,000 \\
\hline
\end{tabular}


Table 4. Cont.

\begin{tabular}{|c|c|c|c|c|c|}
\hline Disease & Clinical Entity & Age Group & Typical Signs & IR & TNE \\
\hline \multirow{5}{*}{ Aujeszky's } & Encephalitis & Piglets infected in utero & Weak piglets, shaking/shivering/sudden death & 0.0001097 & 110 \\
\hline & Encephalitis & Piglets $(<3$ weeks $)$ & $\begin{array}{l}\text { Lethargy, weakness/appetite loss, incoordination/convulsions (vomiting, diarrhoea) incl. } \\
\text { febrile response (up to } 42^{\circ} \mathrm{C} \text { ) }\end{array}$ & 0.000146 & 146 \\
\hline & Encephalitis & Adult pigs & Incoordination of hind limbs and febrile response (up to $42^{\circ} \mathrm{C}$ ) & 0.0008113 & 811 \\
\hline & Respiratory signs & Weaners \& finishers (>3 weeks) & Sneezing/nasal discharge, coughing, dyspnoea & 0.0001097 & 110 \\
\hline & Reproduction & & Vaginal discharge; mummification; agalactia & 0.00032 & 320 \\
\hline \multirow{4}{*}{ PRRS } & Re-exposure & Sows & Reproductive problems incl. abortion, still-birth, and return to service & 0.00275 & 2750 \\
\hline & \multirow{3}{*}{ Acute infection } & Sows \& boars & Anorexia, fever, lethargy, respiratory difficulties, cyanosis & 0.1 & 100,000 \\
\hline & & Nursery piglets & $\begin{array}{l}\text { Poor growth, anorexia, fever, respiratory distress, diarrhoea, anaemia, congenital } \\
\text { abnormalities, weakness, ataxia, haemorrhage, immunomodulation }\end{array}$ & 0.075 & 75,000 \\
\hline & & Weaners \& finishers & Transient anorexia, respiratory disorders and discolouration of the ears & 0.05 & 50,000 \\
\hline \multirow{5}{*}{$\begin{array}{l}\text { Welfare } \\
\text { hazards- } \\
\text { cattle }\end{array}$} & $\begin{array}{l}\text { No access to } \\
\text { water-cattle }\end{array}$ & Cows & Scenario: dairy cattle left with no access to water due to broken pipes & & 5600 \\
\hline & Broken femur-cattle & Cows & Scenario: dairy cow falls on slippery floor and is left until euthanised & 0.001 & 1000 \\
\hline & $\begin{array}{l}\text { Lying on concrete } \\
\text { floor with no } \\
\text { bedding material }\end{array}$ & Cows & $\begin{array}{l}\text { Scenario: dairy cows resting in a free stall } \\
\text { environment }\end{array}$ & 0.01 & 10,000 \\
\hline & $\begin{array}{l}\text { Weather conditions } \\
\text { are too hot }\end{array}$ & Cows & $\begin{array}{l}\text { Scenario: warm summer days }\left(>25^{\circ} \mathrm{C}\right) \\
\text { interrupted by cooler nights. No access to shade during the daytime. }\end{array}$ & 0.9 & 900,000 \\
\hline & $\begin{array}{l}\text { Separation of cow and } \\
\text { calf }\end{array}$ & Calves & Scenario: calf separated within $24 \mathrm{~h}$ of birth & 0.95 & 950,000 \\
\hline \multirow{5}{*}{$\begin{array}{l}\text { Welfare } \\
\text { hazards- } \\
\text { pigs }\end{array}$} & Broken femur-pigs & Sows & Scenario: sow falls on slippery floor with other sows and is pushed around & 0.001 & 1000 \\
\hline & Weaning of piglets & Piglets & Scenario: piglets are weaned $3-4$ weeks after birth & 0.95 & 950,000 \\
\hline & Tail biting & Weaner \& finisher pigs & Scenario: ongoing severe tail biting (part of tail bitten off, blood present) & 0.03 & 30,000 \\
\hline & Crating of sows & Sows & Scenario: sows are crated in farrowing section (from 1 week prior to farrowing) & 0.95 & 950,000 \\
\hline & Feed restriction & Sows & $\begin{array}{l}\text { Scenario: feed provision is reduced to } 30 \% \text { of ad lib during gestation. Sows are housed } \\
\text { together, but most often feed provision is individual }\end{array}$ & 0.98 & 980,000 \\
\hline
\end{tabular}

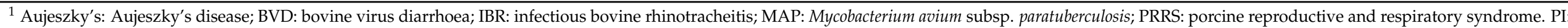
Persistently infected. BCS: Body condition score. 


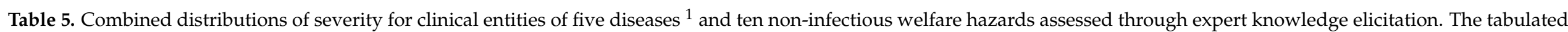
severity scores present the median of the scores from the eight experts for each of the percentiles 2.5, median, and 97.5.

\begin{tabular}{|c|c|c|c|c|c|c|}
\hline Disease & Clinical Entity & AGE Group & Typical Signs & $2.5 p$ & Median & $97.5 p$ \\
\hline \multirow{9}{*}{ BVD } & Transient infection & $\begin{array}{l}\text { Calves } \\
\text { Heifers \& cows }\end{array}$ & Diarrhoea & 1 & 3 & 5 \\
\hline & $\begin{array}{l}\text { Transient infection } \\
\text { with erosions }\end{array}$ & $\begin{array}{l}\text { Calves } \\
\text { Heifers \& cows }\end{array}$ & Mucosal erosions & 3.5 & 5 & 7 \\
\hline & \multirow{2}{*}{ Co-morbidity } & Calves \& heifers & Respiratory disease, diarrhoea & 3 & 4.5 & 7 \\
\hline & & Cows & Mastitis, retained placenta & 2 & 5 & 6 \\
\hline & Repeat breeding & Heifers \& cows & Subclinical & 0 & 0 & 0.5 \\
\hline & Abortion & Heifers \& cows & Abortion early or late after infection & 1 & 2.5 & 4 \\
\hline & Congenital defects & Newborn & Miscellaneous malformations incl. congenital tremor and weak calves & 1.5 & 4 & 7 \\
\hline & PI: animals unthrifty & Calves \& heifers & Weight loss & 1 & 4 & 7 \\
\hline & PI: mucosal disease & Calves \& heifers & Severe diarrhoea and erosion & 7 & 8 & 9.5 \\
\hline \multirow[b]{2}{*}{ IBR } & \multirow[t]{2}{*}{ Acute phase } & Calves, heifers \& cows & $\begin{array}{l}\text { Reduced appetite, dullness, salivation, nasal and ocular discharge, lachrymation, conjunctivitis, } \\
\text { rapid respiration, coughing and pyrexia. May lead to death }\end{array}$ & 2.5 & 6 & 8 \\
\hline & & Calves, heifers \& cows & Diarrhoea and dehydration & 2 & 3.5 & 5 \\
\hline \multirow{5}{*}{ MAP } & \multirow{3}{*}{ Stage III } & Cows & Weight loss/poor condition (BCS 1-2)/chronic wasting & 2 & 3.5 & 5 \\
\hline & & Cows & Intermittent diarrhoea & 1 & 3 & 4.5 \\
\hline & & Cows & Emaciation (BCS 0-1) & 5 & 7.5 & 8.5 \\
\hline & \multirow{2}{*}{ Stage IV } & Cows & Pipe stream diarrhoea & 3.5 & 5.5 & 7 \\
\hline & & Cows & Lethargy & 6 & 8 & 9 \\
\hline
\end{tabular}


Table 5. Cont.

\begin{tabular}{|c|c|c|c|c|c|c|}
\hline Disease & Clinical Entity & AGE Group & Typical Signs & $2.5 \mathrm{p}$ & Median & $97.5 \mathrm{p}$ \\
\hline \multirow{4}{*}{ Aujeszky's } & Encephalitis & Piglets infected in utero & Weak piglets, shaking/shivering/sudden death & 5 & 7 & 8.5 \\
\hline & Encephalitis & Piglets $(<3$ weeks) & $\begin{array}{l}\text { Lethargy, weakness/appetite loss, incoordination/convulsions (vomiting, diarrhoea) incl. } \\
\text { febrile response (up to } 42^{\circ} \mathrm{C} \text { ) }\end{array}$ & 4.5 & 6 & 8 \\
\hline & Encephalitis & \multirow{2}{*}{$\begin{array}{l}\text { Weaners \& finishers } \\
(>3 \text { weeks) } \\
\text { Adult pigs } \\
\text { Weaners \& finishers } \\
\text { (>3 weeks) }\end{array}$} & Incoordination of hind limbs and febrile response (up to $42^{\circ} \mathrm{C}$ ) & 5 & 6.5 & 8 \\
\hline & Respiratory signs & & Sneezing/nasal discharge, coughing, dyspnoea & 3 & 5 & 6 \\
\hline \multirow{4}{*}{ PRRS } & Re-exposure & Sows & Reproductive problems incl. abortion, still-birth, and return to service & 2 & 4.5 & 7 \\
\hline & \multirow{3}{*}{ Acute infection } & Sows \& boars & Anorexia, fever, lethargy, respiratory difficulties, cyanosis & 1 & 2 & 3 \\
\hline & & Nursery piglets & $\begin{array}{l}\text { Poor growth, anorexia, fever, respiratory distress, diarrhoea, anaemia, congenital abnormalities, } \\
\text { weakness, ataxia, haemorrhage and immunomodulation }\end{array}$ & 2.5 & 5.5 & 8.5 \\
\hline & & Weaners \& finishers & Transient anorexia, respiratory disorders and discolouration of the ears & 2.5 & 4 & 6 \\
\hline \multirow{4}{*}{$\begin{array}{l}\text { Welfare } \\
\text { hazards- } \\
\text { cattle }\end{array}$} & $\begin{array}{l}\text { No access to } \\
\text { water-cattle }\end{array}$ & Cows & Scenario: dairy cattle left with no access to water due to broken pipes & 1 & 5 & 9 \\
\hline & $\begin{array}{l}\text { Lying on concrete } \\
\text { floor with no } \\
\text { bedding material }\end{array}$ & Cows & Scenario: dairy cows resting in a free stall environment & 3 & 5 & 6.5 \\
\hline & $\begin{array}{l}\text { Weather conditions } \\
\text { are too hot }\end{array}$ & Cows & $\begin{array}{l}\text { Scenario: warm summer days }\left(>25^{\circ} \mathrm{C}\right) \text { interrupted by cooler nights. No access to shade during } \\
\text { the daytime. }\end{array}$ & 3.5 & 5.5 & 8 \\
\hline & $\begin{array}{l}\text { Separation of cow } \\
\text { and calf }\end{array}$ & Calves & Scenario: calf separated within $24 \mathrm{~h}$ of birth & 2 & 4 & 6 \\
\hline \multirow{5}{*}{$\begin{array}{l}\text { Welfare } \\
\text { hazards- } \\
\text { pigs }\end{array}$} & Broken femur-pigs & Sows & Scenario: sow falls on slippery floor with other sows and is pushed around & 6 & 8 & 9.5 \\
\hline & Weaning of piglets & Piglets & Scenario: piglets are weaned 3-4 weeks after birth & 2 & 4 & 5 \\
\hline & Tail biting & Weaners \& finishers & Scenario: ongoing severe tail biting (part of tail bitten off, blood present) & 4 & 6 & 8 \\
\hline & Crating of sows & Sows & Scenario: sows are crated in farrowing section (from 1 week prior to farrowing) & 3 & 4 & 6.5 \\
\hline & Feed restriction & Sows & $\begin{array}{l}\text { Scenario: feed provision is reduced to } 30 \% \text { of ad lib during gestation. Sows are housed together, } \\
\text { but most often feed provision is individual }\end{array}$ & 2.5 & 4.5 & 5 \\
\hline
\end{tabular}

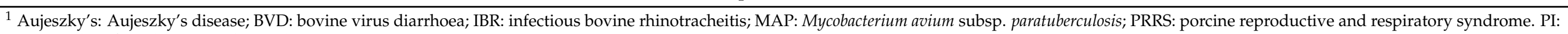
Persistently infected. BCS: Body condition score. 


\section{Combined entities per disease}

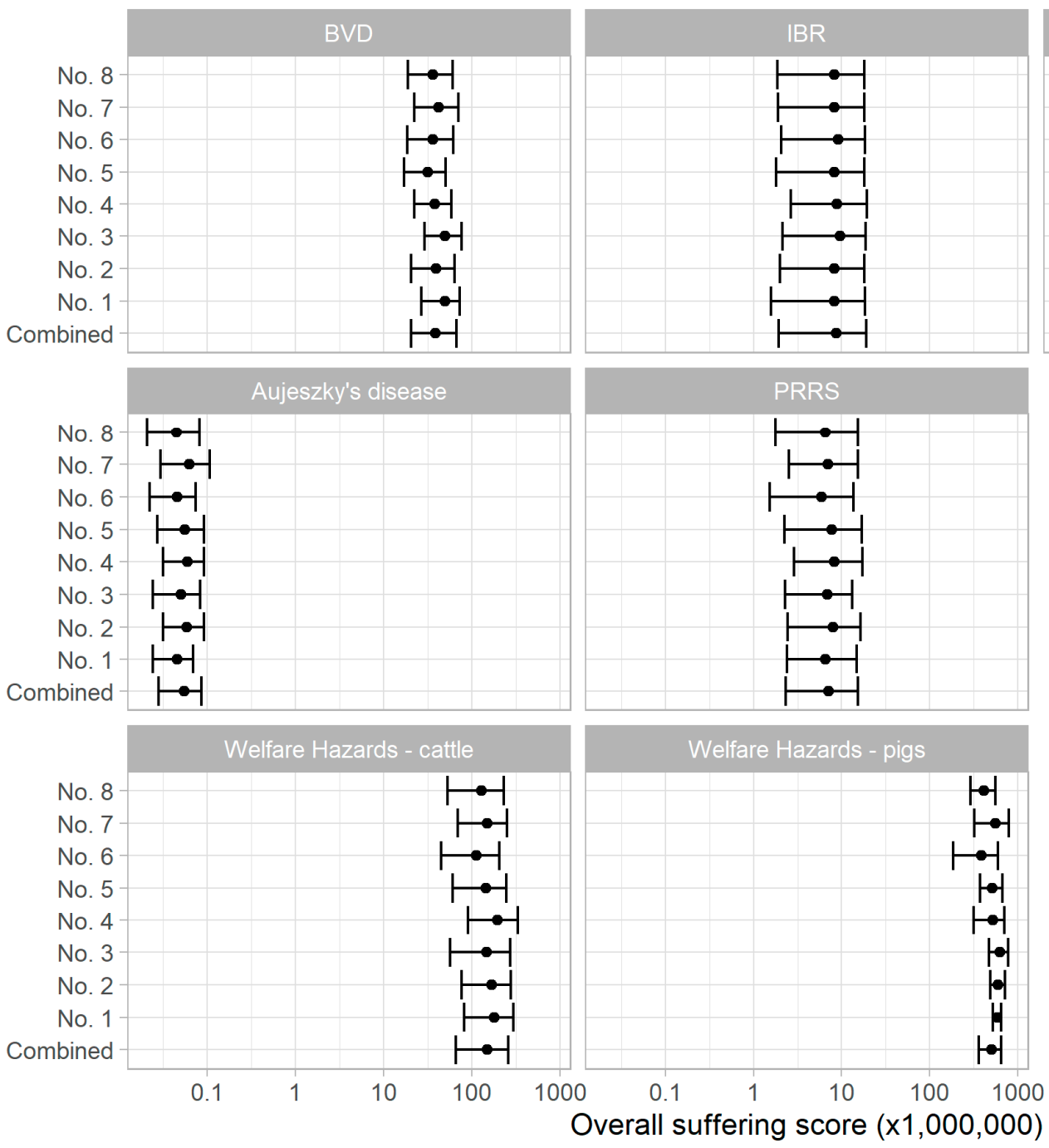

Figure 1. The aggregated suffering scores $(2.5,50$, and 97.5 percentiles) given by eight experts (specified as No. 1-No. 8). 


\section{Combined experts per disease}

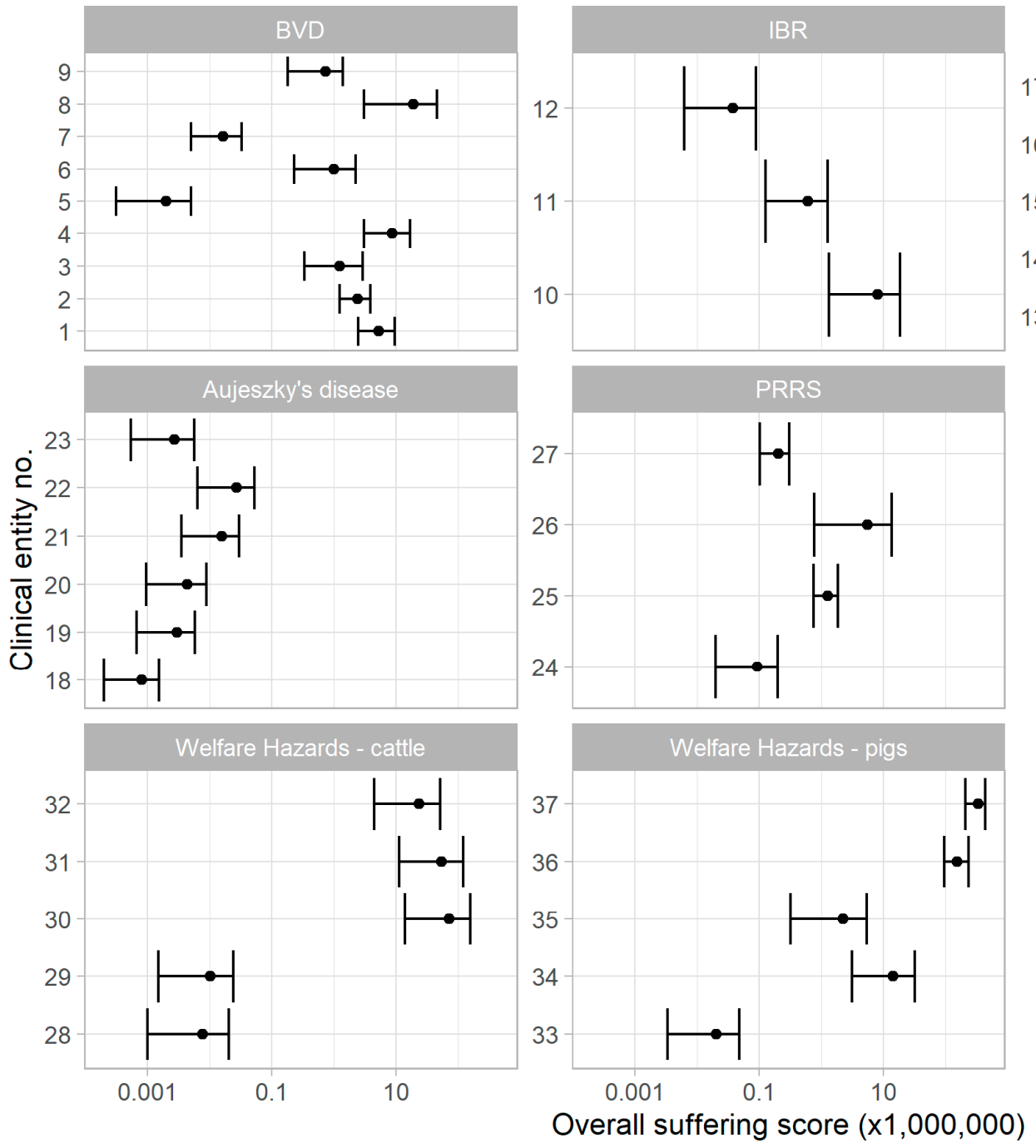

Figure 2. Aggregated suffering scores (2.5, 50, and 97.5 percentiles) by disease condition. The disease entities and welfare hazards are numbered as follows: 1-9, BVD: (1) transient infection; (2) transient infection with erosions; (3) comorbidity (mastitis, retained placenta); (4) comorbidity (respiratory disease); (5) repeat breeding; (6) abortion; (7) congenital defects; (8) persistent infection (unthrifty animals); (9) persistent infection: mucosal disease; 10-12, IBR: (10) acute phase, respiratory version; (11) acute phase, gastro-intestinal version; (12) abortion; 13-17, MAP infection: (13) stage III with chronic wasting; (14) stage III with intermittent diarrhoea; (15) stage III with emaciation; (16) stage IV with pipe stream diarrhoea; (17) stage IV with lethargy; 18-23, Aujeszky's disease: (18) encephalitis (weak piglets); (19) encephalitis (lethargic piglets); (20) encephalitis—weaners and finishers; (21) encephalitis—adults; (22) respiratory signs—finishers; (23) reproductive problems; 24-27, PRRS: (24) re-exposure in sows; (25) acute infection in piglets; (26) acute infection in weaners and finishers; (27) acute infection in sows and boars; 28-32, welfare hazards in cattle: (28) no access to water; (29) broken femur; (30) lying on concrete floor with no bedding material; (31) weather conditions are too hot; (32) separation of cow and calf; 33-37, welfare hazards in pigs: (33) broken femur; (34) weaning of piglets; (35) tail biting; (36) crating of sows; (37) feed restriction for sows. 
Table 6. Suffering scores for four infectious diseases in cattle and two infectious diseases in pigs, five welfare hazards in cattle, and five welfare hazards in pigs. The suffering scores pertain to a population of 1 million animals in a year, but because the durations vary, the effect of short-term incidents (such as no access to water) can be less than for long-term incidents (such as lying on a concrete floor).

\begin{tabular}{cccc}
\hline \multirow{2}{*}{ Disease/Welfare Hazard } & \multicolumn{3}{c}{ Suffering Score $(\times \mathbf{1 , 0 0 0 , 0 0 0 )}$} \\
\cline { 2 - 4 } & $\mathbf{2 . 5}$ lower CL & Mode & $\mathbf{9 7 . 5}$ upper CL \\
BVD & 20 & 39 & 65 \\
IBR & 2.1 & 8.7 & 18 \\
MAP & 17 & 36 & 60 \\
Aujeszky's disease & 0.028 & 0.055 & 0.086 \\
PRRS & 2.4 & 7.1 & 15 \\
WH Cattle: No access to water & 0.001 & 0.007 & 0.019 \\
WH Cattle: Broken femur & 0.002 & 0.01 & 0.024 \\
WH Cattle: Lying on concrete floor with no & 15 & 70 & 162 \\
bedding material & 9.9 & 54 & 119 \\
WH Cattle: Weather conditions are too hot & 4.0 & 24 & 54 \\
WH Cattle: Separation of cow and calf & 0.003 & 0.022 & 0.051 \\
WH Pigs: Broken femur-pigs & 3.3 & 15 & 32 \\
WH Pigs: Weaning of piglets & 0.39 & 2.4 & 5.6 \\
WH Pigs: Tail biting & 94 & 159 & 246 \\
WH Pigs: Crating of sows & 217 & 344 & 463 \\
WH Pigs: Feed restriction & &
\end{tabular}

Aujeszky's: Aujeszky's disease; BVD: bovine virus diarrhoea; IBR: infectious bovine rhinotracheitis; MAP: Mycobacterium avium subsp. paratuberculosis; PRRS: porcine reproductive and respiratory syndrome; WH: Welfare hazard; CL: confidence limit.

\section{Discussion}

To the best of our knowledge, this study is the first to attempt to quantify the impact of specific diseases on animal welfare. For example, it appears that Aujeszky's disease has less impact on pigs than PRRS at population level, while our ranking shows that, for cattle, BVD and MAP are worse than IBR in the endemic situation with no organised control effort/programme. If these assessments are considered valid, the data can be aggregated to country level and the effect of disease control on animal welfare can be estimated and assessed.

In general, we found some surprising results, as clinical entities with painful clinical signs and a short duration had a relatively small effect on animal welfare, although a potentially high prevalence must also be taken into consideration. Therefore, disease entities with a short duration and low prevalence result in a smaller impact on animal welfare, whereas clinical entities with a long duration will have a greater impact at population level. Another finding is the high impact of some of the non-infectious welfare hazards due to their high prevalence (e.g., weaning of piglets and separation of calf and cow). In the present paper, calculations were based on a denominator of 1,000,000 animals to allow for comparison between populations. However, estimations can also be made at country level and to allow for comparison across populations of pigs and cattle. For example, the Danish pig population of $>20$ million pigs produced annually is much bigger than the cattle population of around 1 million.

The numbers may be used to compare diseases, welfare hazards, and for comparison between countries. However, caution should be advised. Firstly, there are limited data on the severity of clinical signs and their distributions available in the literature, and the distributions are often only vaguely described, as are the duration and frequency. Therefore, the aggregation of suffering scores with duration and frequency results in major uncertainty. We therefore used EKE as a tool. EKE is influenced by the views and experiences of the experts involved, which, in turn, are affected by their field experience. Therefore, we used the Delphi method, firstly with individual assessments followed by group discussions, still allowing for individual variation. Some variation was indeed found among experts, but 
no expert seemed to be systematically more uncertain, score diseases higher, or stand out in any other way (Figure 1). Therefore, we chose to combine the estimates from different experts and allow the model to absorb the uncertainty at expert level. Other experts may provide different results, and the model is subject to uncertainty at this level. For example, the literature reviews may not have included all relevant clinical signs, especially the less severe ones. For example, we included "repeat breeding" for BVD, although it is not a severe condition. This was included because breeding can induce stress for cattle, but breeding is also a common event and other causes of repeat breeding exist. Therefore, it could be argued whether or not this should have been included. The same applies to other conditions. For MAP infections, we did not include, e.g., "bottle jaw", where oedema may be present around the jaws. However, this was included in the already described entities and may not have been any more serious than the already described and more predominant features "chronic wasting" and "intermittent diarrhoea", and it was therefore deemed to be unnecessary to include this separately. In general, we do not specifically include the animals' physiological or hormonal responses directly, because no such information was found in the extensive literature searches that we performed. However, in principle, such information is included through the EKE.

Despite these limitations, the model presented here provides an insight into how animal welfare consequences of infectious diseases can be aggregated and quantified at population level. In terms of pig diseases, Aujeszky's disease clearly has less impact on animal welfare than PRRS, which is likely to be due to the prolonged nature of PRRS, despite the disease entity "encephalitis" associated with Aujeszky's disease being given relatively high mode scores of 7 out of 10 for severity in piglets and scores of $6.5-7$ in other pigs. However, the most likely duration of 1 day in piglets resulted in an aggregated score that was relatively low, even though the severity for PRRS was not much lower (5.5 and 4 for nursery pigs and weaners and finishers, respectively), while a longer duration of 7 days (nursery pigs) and 6 days (weaners and finishers) had a major impact. The main drivers of the aggregated scores are therefore duration and population size. In cattle, these combinations resulted in the following ranking of diseases: BVD and MAP > IBR, which is logical, because BVD in the endemic situation is highly prevalent (for transiently infected animals) and of long duration (for persistently infected animals), whereas MAP is of relatively low prevalence but very long duration. The same features (high prevalence and long duration) also have an impact on the non-infectious welfare hazards; a lack of access to water and broken femurs are rare and of short duration and therefore do not have a major impact at population level. However, weather conditions that are too hot can have a long duration and affect the majority of the cattle population, while feed restriction, crating of sows, and early weaning of piglets affect a large proportion of the pig population and for a very long time. Even though the severity may not rank highly, the long duration is a major driver and gives these hazards a similar or greater impact than PRRS. We choose some infections which have been relevant to Danish conditions for the past 40 years. However, the method can also be applied to other infectious diseases. It may be applied to quantification of animal welfare burdens in initiatives such as Global Burden of Animal Diseases [21]. In many of the studies of eradication programmes, animal welfare is mentioned as one of several aspects to be taken into account (e.g., [22-24]); using the methods of the current study, this aspect may be quantified and used in making decisions on eradication strategies.

\section{Conclusions}

We developed an analysis method that can be used to assess the impact of infectious diseases on animal welfare in cattle and pigs at population level. The model suggests that the impact ranking for cattle is: BVD and MAP > IBR, and for pigs: PRRS > Aujeszky's disease. The impact of BVD may on average be similar to 1 week of weather conditions that are too hot per year, and the impact of PRRS is similar to feed restriction, crating of sows, 
and weaning of piglets. However, major sources of uncertainty exist, and these should be taken into account when the results are interpreted.

Supplementary Materials: The following are available online at https:/ / www.mdpi.com/article / 10.3390/ani11113017/s1, Table S1: Data on expert knowledge elicitations on severity, duration and frequency, along with population sizes. Document S1: Disease fact sheets including information from extensive literature searches.

Author Contributions: Conceptualisation, S.S.N.; methodology, S.S.N. and M.D.; formal analysis, M.D.; investigation, S.S.N., H.H., M.D., L.R.N., B.F., N.D.O. and J.F.A.; resources, H.H.; data curation, S.S.N.; writing-original draft preparation, S.S.N. and M.D.; writing-review and editing, S.S.N., H.H., M.D., L.R.N., B.F., N.D.O. and J.F.A.; visualisation, M.D.; project administration, J.F.A. and H.H.; funding acquisition, H.H. All authors have read and agreed to the published version of the manuscript.

Funding: This research was funded by the Knowledge Centre for Animal Welfare, The Danish Veterinary and Food Administration, Glostrup, Denmark.

Institutional Review Board Statement: Not applicable.

Data Availability Statement: Data are available under Supplementary Materials.

Acknowledgments: The authors would like to thank Line Sindahl for participating in the scoring of clinical entities and Sarah Layhe for language editing of this paper.

Conflicts of Interest: The authors declare no conflict of interest.

\section{References}

1. Houe, H.; Nielsen, L.R.; Nielsen, S.S. Control and Eradication of Endemic Infectious Diseases in Cattle; College Publications: Rickmansworth, UK, 2014; ISBN 978-1-84890-156-8.

2. European Parliament. Regulation (EU) 2016/429, “Animal Health Law”, Brussels, Belgium. Available online: https: / / eur-lex. europa.eu/eli/reg/2016/429/oj (accessed on 10 October 2021).

3. Botreau, R.; Veissier, I.; Butterworth, A.; Bracke, M.B.M.; Keeling, L.J. Definition of Criteria for Overall Assessment of Animal Welfare. Anim. Welf. 2007, 16, 225-228.

4. Schrader, L.; Czycholl, I.; Krieter, J.; Leeb, C.; Zapf, R.; Ziron, M. Tierschutzindikatoren: Leitfaden für die Praxis—Schwein; KBTL: Darmstadt, Germany, 2016; p. 74.

5. European Food Safety Authority Guidance on Expert Knowledge Elicitation in Food and Feed Safety Risk Assessment. EFSA J. 2014, 12, 3734. [CrossRef]

6. More, S.; Bøtner, A.; Butterworth, A.; Calistri, P.; Depner, K.; Edwards, S.; Garin-Bastuji, B.; Good, M.; Schmidt, C.G.; Michel, V.; et al. Ad Hoc Method for the Assessment on Listing and Categorisation of Animal Diseases within the Framework of the Animal Health Law. EFSA J. 2017, 15, e04783. [CrossRef] [PubMed]

7. More, S.; Bicout, D.; Botner, A.; Butterworth, A.; Calistri, P.; Depner, K.; Edwards, S.; Garin-Bastuji, B.; Good, M.; Schmidt, C.G.; et al. Animal Welfare Aspects in Respect of the Slaughter or Killing of Pregnant Livestock Animals (Cattle, Pigs, Sheep, Goats, Horses). EFSA J. 2017, 15, e04782. [CrossRef] [PubMed]

8. More, S.; Bøtner, A.; Butterworth, A.; Calistri, P.; Depner, K.; Edwards, S.; Garin-Bastuji, B.; Good, M.; Schmidt, C.G.; Michel, V.; et al. Assessment of Listing and Categorisation of Animal Diseases within the Framework of the Animal Health Law (Regulation (EU) No 2016/429): Aujeszky's Disease. EFSA J. 2017, 15, e04888. [CrossRef] [PubMed]

9. More, S.; Bøtner, A.; Butterworth, A.; Calistri, P.; Depner, K.; Edwards, S.; Garin-Bastuji, B.; Good, M.; Schmidt, C.G.; Michel, V.; et al. Assessment of Listing and Categorisation of Animal Diseases within the Framework of the Animal Health Law (Regulation (EU) No 2016/429): Paratuberculosis. EFSA J. 2017, 15, e04960. [CrossRef] [PubMed]

10. Houe, H.; Larsen, L.E. Proceedings of the XXVI World Buiatrics Congress 2010: Santiago, Chile, 14-18 November 2010; Wittwer, F., Ed.; Novodiseño: Santiago, Chile, 2010; ISBN 978-956-332-961-2.

11. Nielsen, S.S.; Alvarez, J.; Bicout, D.J.; Calistri, P.; Depner, K.; Drewe, J.A.; Garin-Bastuji, B.; Rojas, J.L.G.; Schmidt, C.G.; Michel, V.; et al. Health and Welfare of Rabbits Farmed in Different Production Systems. EFSA J. 2020, 18, e05944. [CrossRef]

12. Houe, H.; Meyling, A. Prevalence of Bovine Virus Diarrhoea (BVD) in 19 Danish Dairy Herds and Estimation of Incidence of Infection in Early Pregnancy. Prev. Vet. Med. 1991, 11, 9-16. [CrossRef]

13. Houe, H.; Ersbøll, A.K.; Toft, N. (Eds.) Introduction to Veterinary Epidemiology; Biofolia: Frederiksberg, Denmark; ISBN 978-87-91319-21-1.

14. Statistics Denmark. Landbrugsstatistik 1985 (Agricultural Statistics 1985); Statistics Denmark: Copenhagen, Denmark, 1986; ISBN 978-87-501-0679-1.

15. Nylin, B.; Madsen, K.G.; Rønsholt, L. Reintroduction of Bovine Herpes Virus Type 1 into Danish Cattle Herds During the Period 1991-1995: A Review of the Investigations in the Infected Herds. Acta Vet. Scand. 1998, 39, 401-413. [CrossRef] [PubMed] 
16. Statistics Denmark. Landbrugsstatistik 1995 (Agricultural Statistics 1995); Danmarks Statistik: Copenhagen, Denmark, 1995; ISBN 978-87-501-0728-6.

17. Ferrouillet, C.; Wells, S.J.; Hartmann, W.L.; Godden, S.M.; Carrier, J. Decrease of Johne's Disease Prevalence and Incidence in Six Minnesota, USA, Dairy Cattle Herds on a Long-Term Management Program. Prev. Vet. Med. 2009, 88, 128-137. [CrossRef] [PubMed]

18. de Paz, X.; Vega, D.; Duran, C.O.; Angulo, J. PRRS Prevalence in Europe: Perception of the Pig Veterinary Practitioners; European Society of Porcine Health Management: Nantes, France, 2015; Volume 7, p. 155.

19. Done, S.H.; Paton, D.J.; White, M.E.C. Porcine Reproductive and Respiratory Syndrome (PRRS): A Review, with Emphasis on Pathological, Virological and Diagnostic Aspects. Br. Vet. J. 1996, 152, 153-174. [CrossRef]

20. Carnell, R. Triangle: Provides the Standard Distribution Functions for the Triangle Distribution. R Package Version 0.12. 2019. Available online: https: / CRAN.R-project.org/package=triangle (accessed on 10 October 2021).

21. Huntington, B.; Bernado, T.M.; Bruce, M.; Devleesschauver, B.; Gilbert, W.; Havelaar, A.; Herrero, M.; Marsh, T.L.; Mesenhowski, S.; Pendell, D.; et al. Global Burden of Animal Diseases: A Novel Approach to Understanding and Managing Disease in Livestock and Aquaculture. OIE Bull. 2021, 40, 567-584.

22. Gong, Q.-L.; Chen, Y.; Tian, T.; Wen, X.; Li, D.; Song, Y.-H.; Wang, Q.; Du, R.; Zhang, X.-X. Prevalence of Bovine Tuberculosis in Dairy Cattle in China during 2010-2019: A Systematic Review and Meta-Analysis. PLoS Negl. Trop. Dis. 2021, 15, e0009502. [CrossRef] [PubMed]

23. Tamba, M.; Pallante, I.; Petrini, S.; Feliziani, F.; Iscaro, C.; Arrigoni, N.; Di Sabatino, D.; Barberio, A.; Cibin, V.; Santi, A.; et al. Overview of Control Programs for EU Non-Regulated Cattle Diseases in Italy. Front. Vet. Sci. 2021, 8, 370. [CrossRef] [PubMed]

24. Schweizer, M.; Stalder, H.; Haslebacher, A.; Grisiger, M.; Schwermer, H.; Di Labio, E. Eradication of Bovine Viral Diarrhoea (BVD) in Cattle in Switzerland: Lessons Taught by the Complex Biology of the Virus. Front. Vet. Sci. 2021, 8, 1012. [CrossRef] [PubMed] 